\title{
Pompeii Live: Performing Objects
}

\author{
Lorna Cruickshanks*
}

\begin{abstract}
On 18 June 2013, Pompeii Live brought the Life and Death in Pompeii and Herculaneum exhibition from the British Museum into over 300 cinemas around the UK and Ireland. This paper draws on empirical research of Pompeii Live and audience experiences of the event, in order to consider: How were the objects featured in Pompeii Live encountered by the audience? What were the factors that shaped meaning and value attributed to them? What role was played by the 'live' in Pompeii Live? As access to museum collections is of growing concern, along with accountability to audiences, museums are likely to continue to trial innovative ways of distributing collections. These new ways of sharing collections and knowledge, through ever changing digital media, further speak to wider questions of what a museum is and what a museum does, challenging traditional notions of access, curation, and interpretation.
\end{abstract}

Key words: museums and film; digital; materiality, event cinema, liveness

\section{Introduction}

Exhibitions are fundamentally theatrical, for they are how museums perform the knowledge they create

Barbara Kirschenblatt-Gimblett Destination Culture: Tourism, Museums and Heritage (1998:3)

On 18 June 2013, over 50,000 people ${ }^{1}$ attended cinema screens around the UK and Ireland to experience the British Museum's Life and Death in Pompeii and Herculaneum exhibition via the 90 minute digital broadcast, Pompeii Live. Pompeii Live was billed as a private tour of the exhibition, hosted by television presenters Peter Snow and Bettany Hughes, along with subject experts including the exhibition's curator, Paul Roberts, and Cambridge Professor of Classics, Mary Beard. When Barbara Kirschenblatt-Gimblett considered the theatricality of a museum, she imagined objects as actors, and labels and interpretation as their script. In Pompeii Live, the Life and Death in Pompeii and Herculaneum exhibition and its objects were given a new context in which to perform. This event marked a wider shift ongoing within museums, which Clare Harris has considered in relation to the rising use of digital technology, towards a more distributive behaviour (2013). As collections and information now have the potential to be shared across a wider range of media and an expanded audience, sites of encounters with collections are relocated and objects re-contextualized. Harris has emphasized the importance of considering what is happening to these 'goods outwards' and the ways in which audiences are engaging with them. What happened when the British Museum's Life and Death in Pompeii and Herculaneum exhibition was brought out of the museum and into nearly 300 cinemas in the UK and Ireland? This paper will draw on empirical research carried out by the author as part of postgraduate studies in 2013, and will address how the objects featured in Pompeii Live were encountered by the audience, the factors that shaped meaning and value attributed to them, and the role played by the 'live' in Pompeii Live. 


\section{Museums and film}

It is tempting to think that technological shifts in museums are a recent development, but in fact the relationship between film and museums can be traced back almost 150 years. Museums have both generated and utilized film within interpretation since the nineteenth century. The early ethnographic film Torres Strait Islanders, which came out of the fieldwork of Alfred Cort Haddon, was captured using a cine camera soon after the invention of the motion picture at the end of the nineteenth century. This piece of work is associated with the early years of anthropological research and collecting at the University of Cambridge and its Museum of Archaeology and Anthropology (Griffiths 1997; Banks 2007). At this time, motion pictures had also been integrated into public events at the American Museum of Natural History, New York, where later in the 1930s the museum also installed the first 'dramagraphs' (a sort of miniature cinema as part of permanent display) (Griffiths 2002). In the earlier part of the twentieth century, film was also used to disseminate exhibitions to a wider public; an amateur short film of the 1924 Empire Exhibition at Wembley, London, can be found in the archives of the British Film Institute. ${ }^{2}$ This film shows a day out at the exhibition for employees of the company Pullars of Perth, Scotland, and it would have been screened in Perth's cinema, attracting a relatively large audience who would enjoy the opportunity to see friends and family on screen, as well as experience an exhibition they would not be able to attend themselves. Later in the twentieth century, film was further integrated into museum interpretation; for example, a documentary introducing the Pitt Rivers Museum and its collections, narrated by David Attenborough, was recorded (and is still shown in the museum today). Moving into the twenty-first century, introductory films are often found within exhibitions, and museums have also emerged as co-producers of fiction feature-length films; in the 2000s, the Musée d'Orsay and the Louvre both commissioned and co-produced fiction films which used their museums as a setting for their stories (Penz 2012).

Since the nineteenth century and the early days of cinema, museums have generated film as well as making use of film within interpretation in order to diversify and increase access to collections, displays and their stories. 'Event cinema' is one of the latest manifestations of this relationship, arguable of a more complex nature and greater scale, and raising further questions about the impact on audience experience and what happens to objects presented through this medium.

The arts have been brought to cinema screens around the world through 'event cinema' since the mid-2000s. Following the first such event in 2006, during which the New York Metropolitan Opera broadcast a performance of Mozart's The Magic Flute live to 100 digitally equipped cinemas around the world, opera companies, theatre companies, and art galleries quickly followed suit (Barker 2013). In 2011, the National Gallery was the first gallery to experiment with this medium, presenting Leonardo Live, a 'hosted tour' of the Leonardo da Vinci: Painter at the Court of Milan exhibition. Two years on, in June 2013, Pompeii Live was the first such event to come live out of a museum. Since then, further experimentations with broadcasting exhibitions and their objects live have taken place, not least at the British Museum, who broadcast the Vikings: Life and Legend exhibition around the world through Vikings Live in 2014, and a 'live tour' of the Defining Beauty: the body in Ancient Greek art exhibition through social media platform Periscope in 2015.

Pompeii Live was unique for its time, not least because it was the first of such productions to place objects and a museum at its core. Based around the exhibition which ran at the British Museum between March and September 2013, Pompeii Live offered a live tour, behind the scenes insights and discussions with subject experts, as well as dramatized scenes of life in Pompeii and Herculaneum. A mix of television and cinema tropes and conventions were evident within the production. In his application of medium theory to Metropolitan Opera event cinema, Heyer examined the amalgamation of television and cinema conventions and asserted that despite similarities, the productions are not a movie (2008). In Pompeii Live the drama, music (which 'made it like an action movie' ${ }^{3}$ ) and framing of the production made it feel more cinematic, while the presenters, documentary segments and live element (including a live question and answer session at the end) made it feel more like television. A new and distinct manifestation of event cinema, Pompeii Live prompted many questions about the impacts of event cinema; impacts on museum, collection and audience. 


\section{Methodology}

In order to gain an understanding of encounters with objects and their stories experienced by the Pompeii Live audience and the additional influential factors, analysis of both the production and audience response was fundamental.

Considering Pompeii Live itself, both the content - or internal narrative - as well as the external narrative - being the story of where, how, when and in what context the film was made and encountered - (Banks 2001; 2007) were considered. Conversations with the curator of the exhibition and members of the interpretation and digital broadcasting teams at the British Museum offered an insight into the aims and experiences of the museum and production. The main focus of this research, however, was the audience reception. Anthropology has played a significant role in bringing the audience into view and applying an ethnographic method to media studies and research (Ang 1991; Crawford and Hafsteinsson 1993; Ruby 2000). From the 1980s, ethnographic studies began to focus on how audiences responded to ethnographic film and television in particular (see for example Lull 1990; Abu-Lughod 2002) and following such approaches, participant observation and interviews were conducted in this study through attendance to a screening of Pompeii Live at a local cinema. A small number of semi-structured interviews were conducted at the cinema immediately after the event as well as subsequent interviews and online questionnaires with individuals who had attended screenings in different cinemas around the UK and Ireland.

Social media activity surrounding Pompeii Live was able to offer a wider and additional insight into audience experience also. As a growing means of communication and self-expression, Twitter is increasingly being used as a data source, and systemic analysis of Twitter-based communication are being established across different disciplines (Bruns and Stieglitz 2013). There was a great deal of activity on Twitter surrounding Pompeii Live, led both by the British Museum and audiences around the UK and world. Through the setup of a Twitter account (evident to others to be for research purposes), comments and exchanges around the Twitter hashtag "\#PompeiiLive'4 fed into this research. Twitter was also made use of to circulate an online survey, which was retweeted and further circulated by numerous Twitter users. While responses to the online survey and exchanges on Twitter were largely not as rich as within interviews, these methods were nonetheless valuable indicators of audience experience and enabled a wider range of responses from individuals who attended this live event at 18 different cinemas.

The audience who attended Pompeii Live included keen museum goers, individuals who were unable to attend the Life and Death in Pompeii and Herculaneum exhibition, as well as those with an interest in attending an innovative event, and those with a professional or academic interest. Some had attended the exhibition already (just less than $50 \%$ ), and some planned to.

Time was also spent getting to know the Life and Death in Pompeii and Herculaneum exhibition; the objects, layout and interpretation including labels and text were all considered. Of course the exhibition audience was also a part of this study. Museum audiences have for decades been brought into light as a lens through which to examine the social uses of cultural institutions, issues of identity, and the place and purpose of museums (Hooper-Greenhill 2011); audience evaluation and visitor studies are now a more fundamental part of what museums do. As with understanding film and television audiences, visitors to exhibitions are understood to be active meaning makers, bringing their own preconceptions, experiences, beliefs and values to the museum, exhibition, objects and interpretation. In the exhibition, participant observation and semi-structured exit interviews, along with observation of visitor behaviour around a selection of objects, was carried out.

The audiences and their experiences of Pompeii Live and Life and Death in Pompeii and Herculaneum were of course varied, What follows in this paper is a consideration of the audience experience of Pompeii Live, and a reflection on the potential impact of the transmediation and distribution of an exhibition and its objects through this medium. 


\section{Materiality of objects in Pompeii Live}

Around 200 objects featured in Life and Death in Pompeii and Herculaneum. A small selection of these featured in Pompeii Live. What happened to these objects as they appeared on screen? How did they 'perform'?

Along with the increased use in digital technology in relation to museum collections, much discussion has centred around a perceived dichotomy and tension between the physical or 'real' and the digital, characterized by an opposition between the 'real' offering permanence, authority and privileged experience, and the 'digital' as popular, temporary and surface level (Witcomb 2007). A concern that a digital 'reproduction' of an artwork causes it to lose some 'authenticity' harks back to Walter Benjamin's influential essay 'The Work of Art in the Age of Mechanical Reproduction' (1968 [1936]) in which he argued that art loses its 'aura' (associated with qualities of unique, traditional and 'authentic') when reproduced through photography or film. Several studies, and particularly ethnographic research, have however challenged this. Projects connecting collections to source communities for example have proven digital evocations or avatars of objects do provoke profound and real reactions (see for example Hess et al 2009; Ngata et al 2012). Carl Hogsden and Emma Poulter have positioned digital objects as neither disconnected nor oppositional to physical counterparts (2012). The experience of digital objects is valid and nuanced, not only as representations or referents but as active agents.

Fiona Cameron has argued that the digital should be freed from a materialist epistemology in order to move beyond the 'cult of the replicant', in which digital objects are compared to a superior physical counterpart (2007). However, a materialist approach can be useful, dependent upon its understood definition. Sandra Dudley's 2010 edited volume Museum Materialities began to unpick and challenge what materiality might in fact mean and might be; challenging the notion of objects as 'information packages', the active role of a person in an object's meaning and existence, sensory experience and emotional affect were emphasized. Perhaps materiality means more than physicality and manifests in different ways. In her work which positions photographs as objects, Elizabeth Edwards has suggested that by considering the materiality of photographs, these objects can to be understood not only in terms of their production, consumption, ownership, and institutionalization, but also their agency and affective qualities $(2001 ; 2010 ; 2012)$. While a lost sense of 'sharing airspace' with objects was noted by some Pompeii Live audience members and, for some, the production 'lacked any 3-dimensional sense of the objects' (online survey participant), sensory and emotional experiences were affected by the objects on screen.

A silver goblet with a relief design was one of the objects featured in Pompeii Live, and one that many participants in this research spoke about. Interestingly, in the physical exhibition, the goblet was waist-height and so viewed from above, making the relief design less accessible to the visitor. While some visitors did bend down to look, it was less of a 'star object' than in Pompeii Live. In the production, the camera zoomed in on the intricate relief design on the outside of the cup of the goblet. Another object which impacted greatly on research participants was a carbonized loaf of bread. Again, high resolution close up shots revealed a great amount of detail, which audience members emphasized: the cracks, an indentation left by the string that would have been tied around it, and a stamp of the slave who had made it, over 2000 years ago. The potential to have close ups of objects seemed to provide audience members with 'more of the object' through revealing physical details of the object, and the materiality was evident.

As well as the close ups which allowed objects to perform, the presenters seemed to play a role in enhancing the sensory experience of the objects on screen. When discussing the carbonized bread, the presenters' conversation emphasized the physical details, and a segment with chef Giorgio Locatelli, who recreated the baking of this bread, offered an additional layer of interpretation. Audience members commented on this moment as being highly evocative of the smells and tastes, the experience being sensory and the object brought to life in this way. Audience members also commented on the weight and delicacy of certain objects which was elicited during a part of the production in which objects from the British Museum's collection of Pompeian archaeology were handled by Bettany Hughes and the curator of the exhibition, Paul Roberts. 
The casts of the individuals who died in the eruption of Vesuvius marking the end of life in Pompeii and Herculaneum provoked particularly strong reactions amongst the Pompeii Live audience. One audience member noted:

the way in which they were presented added humanity and poignancy to the deceased. Close up imagery, along with long takes and no music, allowed you to contemplate the people who died. Such consideration wasn't possible when visiting the exhibition in person ${ }^{5}$

Many were reluctant to speak of the casts as 'objects'; although not actual bodies, they were indexical and evocative of a real person whose void from which they were formed, and this is something audience members responded strongly to. The response of audience members to the casts on screen seems to resonate with an attributable agency of images and what appears in them.

As well as the materiality and real affective potential of the objects on screen in Pompeii Live, the above comment also points towards additional factors such as music, which play a role in shaping the experience that Pompeii Live created. To return to Kirschenblatt-Gimblett, if the objects remained the actors here, what became their script and what of their stage?

\section{The framing of experience}

The framing of knowledge, values, and experience within a museum begins with the architectonics of the building, the cases and lighting, right down to the labelling of a single object (see Bennett 1995; Kirschenblatt-Gimblett 1998; Kratz 2011). In Pompeii Live, how much of this was featured, translated or recreated? What shaped the experience of the exhibition and objects created in Pompeii Live?

The Life and Death in Pompeii and Herculaneum exhibition was laid out to evoke a Roman house. After walking through an evocation of a city and its streets, visitors encountered an atrium, cubiculum (bedroom), hortus (garden), living room and culina (kitchen), and encountered the objects that would have been found in each of these rooms. This spatial approach was not mimicked in Pompeii Live. A new and different narrative was created, taking a chronological approach and examining objects and stories relating to what life would have been like over the final two days in Pompeii and Herculaneum. The objects were re-contextualized for Pompeii Live and the story told in a new way.

While exhibitions are of course curated, and visitor behaviours and experiences are accordingly influenced, Pompeii Live audience members seemed to feel their experience of the Life and Death in Pompeii Herculaneum and its objects 'was more controlled...you weren't able to interact with the objects as you would like to'6. Less choice was possible in the experience and less agency accorded to the visitor, including 'no opportunity to revisit other objects $^{\prime 7}$. Corinne Kratz has asserted that visitors create meaning and understanding from objects and exhibition rooms as 'synergetic and synthetic wholes that are more than the sum of their parts. Juxtapositions, contrasts, unspoken assumptions, and spatiotemporal flows' (Kratz 2002:93). As noted above, Pompeii Live followed a different narrative to the exhibition and showed objects and spaces in a new order. Subsequently, audience members formed meaning through the alternative connections and relationships enabled on screen and in the production. For example, during the part of Pompeii Live based around the evening, objects from the street, cubiculum, hortus, and living room sections of the exhibition were focussed upon. Less potential to revisit objects and move between objects in a number of ways, as well as different relationships being presented in Pompeii Live, meant audiences could not explore the exhibition and objects in their own ways.

As well as the content of the production, there are additional factors framing audience experience. Notably here, the physical cinema space provided an interesting context for audience encounters with an exhibition and its objects. Many audience members described Pompeii Live as atmospheric and exciting, which largely seemed associated with the cinema space and its social norms. Ethnographic studies have shown that local practices involved in attending the cinema vary (see Dickey 1993 and Srinivas 1998 in India; Hahn 1994 in Tonga; Larkin 1997 in Nigeria). In some ways Pompeii Live audience members were drawn to act 
as if they were in a museum as well as in a cinema, producing some tension and confusion. For example, largely in the UK, audiences might talk before and after a film, but not during, and watching a film is largely solitary. In exhibitions, social interaction has been positioned as an important part of visitor experience and meaning making (Kratz 2002). Audiences of Pompeii Live seemed undecided about talking in the cinema. Another tension could be seen as audiences were encouraged to use Twitter via their mobile devices to share ideas and questions throughout the production, a behaviour not normally associated with cinema-going. At the Cambridge Cineworld, staff from the Museum of Classical Archaeology led object handling before the screening of Pompeii Live, again merging behaviours and expectations associated with museums and cinemas. The ways objects were encountered through Pompeii Live were framed by many different factors.

\section{The 'live' in Pompeii Live}

In its marketing and promotion, the British Museum heavily emphasized the 'live' in Pompeii Live, and further surrounded the event with additional live digital content. In recent years, the meaning and significance of 'liveness' has been considered within studies of performance, television, as well as music, and to a lesser extent in film studies and studies of the digital. Although different aspects of 'liveness' have been emphasized, Martin Barker has suggested that 'live' generally seems to signify something immediate, simultaneous and less mediated (2013). Philip Auslander has positioned 'liveness' in opposition to 'mediatized' experience and concluded that the concept of 'liveness' is fluid, changing and historically contingent (2008). Tracing the development of 'liveness' alongside technology, Auslander found that 'liveness' only entered discourse when there was something created to exist in opposition to it i.e. when there was a possibility of having something other than live. The one-time opportunity element of 'liveness' seemed to be a pull for many in the audience of Pompeii Live.

Many Pompeii Live audience members questioned how much of Pompeii Live was in fact live, as well as the necessity or benefit of it. In his research into audience responses to what he terms the 'livecasting' of theatre and opera, Barker identified five practical dimensions of 'liveness': immediacy, intimacy, buzz, expanding oneself, and being (in) the audience (Barker 2013:65-66). Although Barker's research did not consider museum or gallery broadcast events, these dimensions can be explored in relation to Pompeii Live. The immediacy of liveness is reflected in the audience's awareness that something could go wrong, the reaction to the on screen countdown in the minutes before Pompeii Live began, and the introductory sweeping shot over the museum's gates and up the museum steps, all of which fostered a spatial and temporal liveness. Through the question and answer session at the end, in which the presenters addressed questions posed by the audience and in addressing the audience, the sense of immediacy was enhanced. Resonating with intimacy, Pompeii Live audience members spoke of the personality of the presenters: 'it was good to see two academics enjoying their work and having a bit of a laugh'8. Interestingly the picture quality seemed to aid this intimacy too: 'I found myself noticing details on the presenters'. The buzz also resonated, reflected for example in the countdown to the event and the excited chatter in advance of the screening.

The large amount of activity on social media in the days leading up to Pompeii Live and on the day of the event speaks to Auslander's suggestion that liveness is associated with a sense of simultaneity, the evocation of human relationships, and a presence (2008; 2011). Social media, and Twitter in particular, is itself based on live communication, perhaps supporting audiences on these platforms to engage with this activity and its liveness more. The idea of simultaneity was in fact raised by one interviewee who highlighted an awareness of knowing that the presenters were in the museum and knowing that others around the UK were in cinemas watching simultaneously. Speaking to the idea of an Andersonian imagined community (1983), viewers imagine a community made up of other viewers and participants at the museum. This is not about nationhood, as it was for Anderson, but about a communal shared experience of a particular event. The live element shaped a collective experience and a buzz, affecting the audience's experience of Pompeii Live.

In Auslander's attempts to understand the concept of 'live' he has also rejected that there are intrinsic properties of 'liveness'. He suggests audience experience and willingness to 
embrace the 'liveness' is key (2011). While many Pompeii Live audience members questioned its 'liveness', some seemed disappointed by its uncertainty whilst others felt there was no impact on their experience. In the week following the 18 June event, several cinemas held 'encore' re-screenings, which may have shed more light on the significance of 'liveness'.

\section{Conclusion}

Pompeii Live signified an on-going shift within the museological landscape which has seen museums increasingly consider new ways to increase access to collections for a wider range of audiences, as well as tell new, different and multiple stories. The objects remained a focal part of the experience of the audience of Pompeii Live, and, supporting the shift in discourse which understands objects encountered in different media as real and valid, the audience were interested in, moved by and learned from them. Whilst certain aspects of the objects were lost, others were enhanced on screen, and their potential to be affective and speak to audiences remained. These encounters with the objects, as well as the experience of the wider exhibition and event, were shaped by several factors; from obvious shifts in narrative and a controlled navigation of the exhibition, to the more subtle influences such as the context of being in a cinema environment. Although elements of 'liveness' were present in Pompeii Live, and while it added to the sense of occasion, it did not seem to have a great impact on audience experience of the exhibition and objects. This is, however, something that could be researched further. Pompeii Live was the first manifestation of museum-based event cinema, and museums have since slowly continued to experiment with new possibilities brought with digital media. As access to museum collections is of growing concern, along with accountability to audiences, museums are likely to continue to trial innovative ways of distributing collections, re-contextualizing objects and telling multiple stories. These new ways of sharing collections and knowledge, through ever changing digital media, further speak to wider questions of what a museum is and what a museum does, challenging traditional notions of access, curation, and interpretation.

Received: 26 August 2014

Finally accepted: 24 October 2016

\section{Notes}

1 Mitchell reported that Tim Plyming, Executive Editor of Pompeii Live, shared this figure at the 2013 CineEurope conference.

2 Available at: http://www.screenonline.org.uk/film/id/854232/index.html [Accessed 05/04/2016]

3 Anonymous interview participant, notes taken by author, 19 ${ }^{\text {th }}$ June 2013

4 On Twitter, tweets (messages) can be prefixed with a hashtag, \#, in order to make communicative exchanges around a particular term easily searchable. I was able to follow real-time feeds of all tweets posted by any user containing \#PompeiiLive.

5 Anonymous online survey participant, survey created using and hosted by Qualitrics, June 2013, response report downloaded 25 July 2013

6 Anonymous online survey participant, survey created using and hosted by Qualitrics, June 2013, response report downloaded 25 July 2013

7 Anonymous online survey participant, survey created using and hosted by Qualitrics, June 2013, response report downloaded 25 July 2013

8 Anonymous online survey participant, survey created using and hosted by Qualitrics, June 2013, response report downloaded 25 July 2013 
9 Anonymous online survey participant, survey created using and hosted by Qualitrics, June 2013, response report downloaded 25 July 2013

\section{References}

Abu-Lughod, L. (2002) 'Egyptian Melodrama- Technology of the Modern Subject?' in Faye Ginsburg, Lila Abu-Lughod and Brian Larkin (eds) Media Worlds: Anthropology on New Terrain, 115-133, Los Angeles: University of California Press

Anderson, B. (1983) Imagined communities: reflections on the origin and spread of nationalism, London: Verso

Ang, I. (1991) Desperately Seeking the Audience, London: Routledge

Auslander, P. (2008) [1999] Liveness; Performance in a mediatized culture, Oxfordshire: Routledge

(2011) 'Digital Liveness: about digital liveness in historical, philosophical perspective.' At transmediale conference 3 February 2011. Available at: http://vimeo.com/20473967 [Accessed 31/07/2013]

Banks, M. (2007) Using Visual Data in Qualitative Research, London: Sage

Barker, M. (2013) Live to your local cinema; The remarkable rise of livecasting, Basingstoke: Palgrave Macmillan

Benjamin, W. 1968 [1936] The Work of Art in the Age of Mechanical Reproduction, in Hannah Arendt (ed) Illuminations New York: Schocken Books

Bruns, A. and Stieglitz, S. (2013) 'Towards more systematic Twitter analysis: metrics for tweeting activities', International Journal of Social Research Methodology 16 (2) 91 108

Crawford, P.I. and Hafsteinsson, S. B. (1993) The Construction of the Viewer: Media Ethnography and the Anthropology of Audiences. Proceedings from Nordic Anthropological Film Association 3, Denmark: Intervention Press

Dickey, S. (1993) Cinema and the Urban Poor in South India, Cambridge: Cambridge University Press

Dudley, S. (2010) Museum Materialities; Objects, Engagements, Interpretations, London: Routledge

Duncan, C. (1991) 'Art Museums and the Ritual of Citizenship' in Ivan Karp and Steven D. Lavine (eds) Exhibiting Cultures: The Poetics and Politics of Museum Display, 88103, Washington: Smithsonian Institution Press

Edwards, E. (ed) (2001) Raw Histories: Photographs, Anthropology and Museums, Oxford: Berg

(2010) 'Photographs and History; Emotion and materiality' in Sandra Dudley (ed) Museum Materialities: Objects, Engagements, and Interpretations, 21-38, London: Routledge

(2012) 'Objects of Affect: Photography beyond the image', Annual Review Anthropology 41 221-234 
Griffiths, A. (1997) 'Knowledge and Visuality in Turn of the Century Anthropology: The early Ethnographic Cinema of Alfred Cort Haddon and Walter Baldwin Spencer' Visual Anthropology Review 12(2) 18-43

(2002) Wondrous Difference; Cinema, anthropology and turn-of-the-century visual culture, New York: Columbia University Press

Hahn, E. (1994) 'The Tongan Tradition of Going to the Movies' Visual Anthropology Review 10(1) 103-111

Harris, C. (2013) 'Digital Dilemmas: The Ethnographic Museum as Distributive Institution' Journal of the Anthropological Society of Oxford 5(2) 125-136

Hess, M., Robson, S., Millar, F.S., and Were, G. (2009) 'Niabara- the Western Solomon Islands War Canoe at the British Museum 3D documentation, virtual reconstruction and digital repatriation' Proceedings from the 15th International Conference on Virtual Systems and Multimedia. http://discovery.ucl.ac.uk/1305320/1/1305320.pdf

Heyer, P. (2008) 'Live from the Met: Digital Broadcast Cinema, Medium Theory, and Opera for the Masses' Canadian Journal of Communication 33 591-604

Hogsden, C. and Poulter, E. (2012) 'The real other? Museum objects in digital contact networks' Journal of Material Culture 17(3) 265-286

Hooper-Greenhill, E. (2011) 'Studying Visitors', in Sharon Macdonald (ed) A Companion to Museum Studies, 362-375, Chichester: Blackwells

Kirschenblatt-Gimblett, B. (1998) Destination Culture: Tourism, Museums and Heritage, Los Angeles: University of California Press

Kratz, C. (2002) The Ones that are Wanted: Communication and the politics of representation in a photographic exhibition, Los Angeles: University of California Press

(2011) 'Rhetorics of Value: Constituting Worth and Meaning through Cultural Display' Visual Anthropology Review 27(1) 21-48

Larkin, B. (1997) 'Lovers: Media and the Creation of Parallel Modernities' Africa: Journal of the International African Institute 67(3) 406-440

Lull, J. (1990) Inside Family Viewing: Ethnographic Research on Television's Audiences, London: Routledge

Mitchell, W. (2013) 'CineEurope day 3: Paramount sequels, Pompeii Live success.' Screen Daily http://www.screendaily.com/news/distribution/cineeurope-day-3-paramountsequels-pompeii-live-success/5057785.article?referrer=RSS

Ngata, W., Ngata-Gibson, H. and Salmond, A. (2012) 'Te Ataakura: Digital taonga and cultural innovation' Journal of Material Culture 17(3) 229-244

Penz, F. (2012) 'Museums as Laboratories of Change; The Case for the Moving Image', in A. Dalle Vacche Film, Art, New Media: Museums without Walls? 278-300, Basingstoke: Palgrave Macmillan

Ruby, J. (2000) Picturing Culture, Chicago: University of Chicago Press

Srinivas, L. (1998) 'Active Viewing: An ethnography of the Indian film audience' Visual Anthropology 11(4) 323-353 
Witcomb, A. (2007) 'The materiality of virtual technologies: A new approach to thinking about the impact of multimedia in museums', in F. Cameron and S. Kenderline (eds) Theorising Digital Cultural Heritage: A Critical Discourse, 35-48, London: MIT Press

*Lorna Cruickshanks currently works in the Access and Audience Development team at the Geffrye Museum as well as the Community Partnerships Team at the British Museum. In 2013, she completed her MSc in Visual, Material, and Museum Anthropology at the University of Oxford. Lorna is interested in the multiple stories, histories, and identities connected to objects, and how museums negotiate and navigate these, as well as the roles museums play in society. Her work bringing diverse audiences together with museum collections is grounded in an interest in what objects can do for people, and what people can bring to objects. Lorna is a founding contributor to the blog and Twitter collective, Sensible Culture, exploring issues in sensory, material and digital anthropology.

Lorna Cruickshanks

Community Partnerships Team

British Museum

Great Russell Street

London WC1B 3DG

lorna.cruickshanks@googlemail.com

British Museum phone: 02073238972 